\title{
DOĞANHİSAR MEZAR STELİ
}

\author{
Prof. Dr. Asuman BALDIRAN \\ Selçuk Üniversitesi Edebiyat Fakültesi \\ Arkeoloji Bölümü \\ abaldiran@yahoo.com
}

\author{
Arş. Gör. Nizam ABAY \\ Selçuk Üniversitesi Edebiyat Fakültesi \\ Arkeoloji Bölümü \\ nizamabay21@gmail.com
}

ORCID ID: http://orcid.org/0000-0002-8334-4436

ORCID ID: http://orcid.org/0000-0002-6799-9395

\section{Öz}

Doğanhisar günümüz coğrafyasında Konya iline bağlı bir ilçedir. Sultan Dağları'nın kuzeydoğu eteklerinde yer almaktadır. Konya il merkezine $122 \mathrm{~km}$. uzaklıktadır. Antik Dönem yollarının kavşak noktalarından dördü ilçe sınırları içerisinde, biri de ilçe sınırındadır. Bilimsel açıdan yüzey araştırmaları dışında arkeolojik araştırma yapılmamıştır. Phrygia Bölgesi sınırları içerisine dahil edildiği bilinen Antik Dönem yerleşiminin adının "Meteos" olarak geçtiğini görüyoruz. İlçe merkezinde çeşitli hafriyatlar sırasında ele geçmiş olan çok sayıda arkeolojik malzeme bulunmaktadır. Bu malzemelerin bir kısmı Halil Çıvgın Parkında, bir kısmı cami duvarlarında şpolyen (devşirme) malzeme olarak kullanılmıştır. Söz konusu malzemeler, mezar stelleri, lahit gövde ve kapakları, kitabeli parçalar, bezemeli mimari elemanlar olarak sıralanabilir. Bu çalışmada ele alacağımız mezar steli de 2002 yıllarında ilçenin Ezze Mahallesi, Cumhuriyet Caddesinde Ezze Camii'nin önünde yapılan kanalizasyon çalışması sırasında ele geçmiştir. Sağlam bir mezar stelidir. Stelin ele geçtiği alan yöre halkı tarafından "Eski Mezarlık Alanı" olarak tanımlanmaktadır. Aynı alanda mezar steli ile birlikte üst kısmı kırık, çelenk figürlü bir başka mezar steli parçası da üzerindeki 7 satırlık Grekçe kitabe ile dikkat çeker. Çalışmamızın konusunu oluşturan stel yerel kireçtaşından yapılmış olup üzerinde yer yer aşınma ve kireçlenme görülmektedir. Tapınak ön cephesi görünümünde işlenmiş mezar stelinin üzerinde bir bayan büstü ve beş satırdan oluşan Grekçe yazıt bulunmaktadır.

Anahtar Kelimeler: Doğanhisar, stel, yazıt.

\section{GRAVE STELE FROM DOĞANHISAR}

\section{Abstract}

Doğanhisar is located in the north-east of Sultan Mountains and $122 \mathrm{~km}$. far from the center of Konya. Four of the ancient crossroads are in the border and one of them is on the border line of the town. There has not been any scientific study in this region except for few surveys. Ancient name of the settlement of this town was "Meteos" and it was in the borders of Phrygia region. During the various construction excavations, a large number of Archaeological materials have been uncovered in the center of the district. Some of these materials were at Halil Çivgin Park and some of them can be seen as part of the walls of the mosque as reused (spolyen) material. These materials can be listed as grave steles, sarcophagi parts and decorated architectural element sandals. In this study, we will deal with a solid grave stele which was found during a canalization excavation in the district. This site is referred as "Old Cemetery" by locals. Stele which is the subject of our study is made by domestic lime stone and formed like a temple facade. The upper of the front side has a female bust and there is a 5 lines inscription in Greek under it.

Keywords: Doğanhisar, stele, inscription. 


\section{GİRIŞ}

Antik Dönemde Doğanhisar Phrygia Paroreios (Dağlık Frigya) olarak adlandırılan coğrafyada yer almaktadır. Bölgede yer alan antik yerleşimlerin lokalizasyonu hala tartışmalı olduğu için özellikle Doğanhisar'ın da yer aldığı Sultan Dağlarının kuzey bölümünde lokalizasyon tam olarak belirlenmiş değildir (Tirpan- Sütçüoğlu 2012). Konum olarak, doğuda Ilgın, güneyde Hüyük, batıda Isparta, kuzeybatıda Akşehir ile kuzeyde Ilgın'ın Argıthanı kasabasına komşudur.

Doğanhisar yerleşiminin eski isminin "Metyos veya Meteos" olduğundan söz edilir (Uçan 2008: 173). Bu isim de Doğanhisar'daki Cuma Çeşmesi'ndeki bir kitabedeki "MANETZOS" yazıtına ithafen söylenmiştir. Ancak bu kentin ismini açıklayıcı bir etnikon gibi durmamaktadır (Konyalı 1945: 608).

Antik kaynaklar Hadrianapolis kentinin Philomelion'dan İkonium'a giden yol üzerindeki bugünkü Koçaş kasabası olarak lokalize edilmesi gerektiğini belirtir (Cox- Cameoron: 1937: 184). Ramsay'a (1960: 445-6/4) göre Doğanhisar, Dağlık Phrygia'da yer alan Hadrianapolis kenti olmalıdır. Ancak bazen Hadrianapolis bazen Thymbrion kenti olarak da lokalize edilir (Ramsay 1939: 184). Ramsay Thymbrion kentinin Phrygia Paroreia (Dağlık Frigya) bölgesinde yol güzergahı üzerinde kalabalık bir şehir olduğunu belirtir (Ramsay 1887: 489; Sevin 2001: 208). Bu kent olasılıkla Roma İmparatorluk Çağında Hadrianapolis adını almıştır (Talbert 2000: 96; Sevin 2001: 208). Thymbrion adı Ksenophon'da da geçer: Thymbrion'a gelen ve buradan hareket eden Cyrus'un ordusu 2 günlük yürüyüşle Ksenophon'un yerleşime elverişli dediği Tyraion'a gelmişlerdir (Ksenophon I.2. 13-20). Pek çok uygarlığın yerleşimine tanık olan ilçe merkezinde yapilan arkeolojik araştırmalarda oldukça fazla buluntu ele geçmiştir.

Bu çalışmamızda Doğanhisar'da kanalizasyon çalışması sırasında bulunup, Konya Arkeoloji Müzesine bağış yoluyla gelen Roma Dönemine ait mezar steli ${ }^{1}$ değerlendirilmiştir. Tapınak cephesi biçiminde işlenmiş olan stelin tabanında çerçeve içine alınmış balık pulu süslemesi vardır². Onun üzerinde bir silmeyle oluşturulmuş plaster kaidesi vardır (Res. 1a-b). Bu kaidenin üstünde torus olarak adlandırabileceğimiz dışa doğru hafifçe çıkıntı yapan topuk kısmı bulunur. Bu torus üzerinde baklava motifleri bezemesi görülür. Baklava dilimlerinin içinde ve aradaki boşluklarda boncuk şeklinde tasarlanmış kabartmalara yer verilmiştir (Res. 2a). Torus üzerinde bulunan 1 $\mathrm{cm}$.lik silmeden sonra iç bükey formda plaster tabanına ulaşan bölüm yer alır. Stelin iki kenarını sınırlandıran plasterler, yanlardan, üst ve alt kısımlardan içe doğru 2 şer cm'lik bantlarla çerçeve içine alınmıştır. Bu çerçeve içinde birbirine dolanmış sarmaşık motifi işlenmiştir. Sarmaşıkların birbirine dolanmasıyla oluşan boşlukların içleri de sarmaşık yaprakları ile doldurulmuştur. Plasterlerde oluşturulan bu süsleme türü özellikle Roma Döneminde sevilerek kullanılan ranke bezemesinin stilize edilmiş bir örneği gibi durmaktadır. Plasterlerin üzerinde dışa doğru çıkıntı yapan düz bir silme yer alır. Bu silme üzerine bezemeli başlıklar yerleştirilmiştir. Başlıklarda dışa doğru açlan üç yaprak görülmektedir. Bu yaprakların arasından uç kısımları daire şeklinde sonuçlanan tomurcuklar çıkmaktadır (Res. 2b). Benzer tarzda plasterler üzerinde dışa çıkıntı bir silme ve üzerinde yaprak betimlemeleri işlenmiş bir başlı̆̆ı Konya Arkeoloji Müzesinde sergilenen (Emekli 2015: 38, Res. 3) ve Laodikeia Combusta antik kentinde bulunan bir başka stelde de görmekteyiz (William 1956: 8, 9, Kat no: 46, 52, Lev. 3).

Başlık üzerinde dörtgen, düz bir silme yer alır. Tapınak mimarisine uygun olarak fascialara ayrılmış friz ve üzerindeki dil bezemeleri olan arşitrav gelmektedir. Arşitrav üzerindeki her dil motifinin içine kaidede olduğu gibi daire formlu kabartma motifler yerleştirilmiştir. Üst kısımdaki yatay geisonda diş sırası işlenmiştir. Yatay geison üzerine üçgen alınlık oturtulmuştur. Alınlık

\footnotetext{
${ }^{1}$ Stel envanter no: 2006.6.1, Yükseklik: 2.10 cm, Genişlik: 47 cm, Derinlik: 26 cm, Alınlık Taban Genişliği: 54 cm, Stel Taban Genişliği: $57 \mathrm{~cm}$.

2 Benzer örnekler için Phrygia Bölgesinde yer alan Laodikea Combusta antik kenti mezar stellerine bakınız (William 1956: 3 , Kat no. 12, 14, Lev.12).
} 
boşluğuna yuvarlak formlu bir kalkan ${ }^{3}$ yerleştirilmiştir. Eğik geisonda alınlığa doğru uzanan diş sırası görülmektedir. Bu eğik geisonlar profilli yapılmıştır ${ }^{4}$. Stel bir tapınağın ön cephesini andırır şekilde düzenlenmiş olup form olarak benzer örnekleri daha çok Phrygia Bölgesi Roma Dönemi yerleşimlerinde karşımıza çıkmaktadır.

Örneğin Dorylaeum antik kentinde bulunan stelin (Cox- Cameoron: 1937: 35, Kat no. 61, Lev. 25) tabandan alınlığa doğru daralıp enlemesine dikdörtgen form oluşturması, stelin ana gövdesinin yanlarındaki plasterler ve üçgen alınlık yapısı Doğanhisar steli ile benzeşen özellikleri olarak yorumlanabilir.

Stelin biçimsel formuyla karşılaştırma yapacağımız bir diğer örnek yine Dorylaeum antik kentinde Çakırlar Köprüsü yakınlarında bulunmuş mezar stelidir (Cox-Cameoron: 1937, 36, Kat no. 64, Lev. 25). Stelin tabandan alınlığa doğru daralması, stelin ana bezeme alanının köşelerinde alçak kabartmalı ve başlıklı plasterler ve stel alınlığını çevreleyen bantların kalınlığı gibi yapısıyla Doğanhisar steline yakın benzerlik oluşturmaktadır.

Kadınhanı buluntusu olan MS 1. yüzyılın ilk yarısına tarihlenen Konya Arkeoloji Müzesinde korunan 1708 envanter numaralı mezar steli (Mclean 2002: Kat No. 146, fig.159) Doğanhisar mezar steline biçimsel olarak benzemektedir. Şematik yapıdaki naiskos formlu Konya steli, akroterler, alınlık, alınlığın ortasında yer alan kalkan, bezeme alanının yanlarda plasterle sınırlandırılması, plaster başlıklarındaki üç yaprak dilimi bezemesi ve alınlıktan tabana doğru daralması gibi özellikleriyle Doğanhisar steline benzemektedir.

Stelin üçgen alınlığın en üstünde ise palmet bezemeli tepe akroteri ve yan akroterler kapalı palmet formunda yerleştirilmiştir. Tepe akroterinin üzerinde bulunan tam palmet süsü ve kemerin etrafını çevreleyen palmet yaprakları betimi alçak kabartma olarak verilmiştir. Dorylaeum antik kentinde Emirler Mahallesinde bulunan mezar stelinde de üçgen alınlık üzerindeki akroterin üzerinde bulunan kapalı tam palmet süsü ve kemerin etrafını çevreleyen palmet yaprakları betimi, Doğanhisar steline benzer uygulama olarak gösterilebilir (Cox- Cameoron 1937: 38, Kat no. 64, Lev. 26).

Karşılaştırma yapacağımız bir diğer örnek Konya arkeoloji müzesinin deposunda korunan envanter numarası 91 olan mezar stelidir. Erken Roma İmparatorluk Dönemine ait stelin üçgen alınlığının üstünde kapalı palmet bezemeli tepe ve yan akroterlerin görülmesi çalışmamıza konu olan stelle benzeyen yönünü oluşturmaktadır (Emekli 2005: 54, Res. 22). Bu tarz biçimlendirme hem mezar sahibinin ekonomik durumunun iyi olduğunu hem de steli yapan ustanın tapınak mimarisi konusunda bilgili olduğunu göstermektedir.

Stelde dikkat çeken bir ayrıntı da, yukarıda bahsettiğimiz yani plasterlerin kaide kısmından başlayıp tepe akroterine kadar olan bezeme özelliklerinin stelin yan yüzündeki payanda işlevi gören kısımda da devam etmesidir (Res. 3). Bu biçimsel yapıdan da anlıyoruz ki stel muhtemelen bir niş içerisinde yer alıp üç boyutlu bir şekilde tasarlanmıştır. Stelin arka kısmı ise masif bir blok şeklinde olup kabaca tıraşlanmıştır.

Stelin üst bölümüne payandalar arasında kalan boşluğa bir kadın büstü yerleştirilmiştir. Büst dikdörtgen formlu bir altlık (platform) üzerine işlenmiştir. Konya Arkeoloji Müzesinde figürlerin benzer tarzda dikdörtgen çıkmalar üzerine oturtulduğu başka steller de vardır (Emekli 2015: 54,57,66, Res. 22, 26, 35). Ayrıca Lydia Bölgesi mezar stellerinde de üçgen alınlıklı ve çıkmalı stel örnekleri mevcuttur (Işık 1988: Kat no: 4, 6, 11, 12, 13). Bu bayan büstü pudicitia ${ }^{5}$ tipinde

\footnotetext{
${ }^{3}$ Naiskos formlu stellerde alınlığın köşeli bant şeklindeki bir simayla çevrilmesi ve alınlık ortasında bir rozet ya da kalkan işlenmesi yaygın bir betimleme tekniği olarak karşımıza çıkmaktadır (Yaylalı 1979: 11; Zanker 1994: 215).

${ }^{4}$ Mezar stellerinin bir kısmı mimari yapılarda görülen diş kesimi (geisipodes), yumurta-ok silmesi (ovolo), kyma lotus palmet bezemeleri içermektedir. Bunlar üretimin uzun bir sürece bağlı olduğu merkezlerde gelişmiş örnekler olarak yorumlanmiştır (Waelkens 1986: 11).

5 Pudicitia motifi, Ağlayan Kadınlar Lahdi ve Klasik Dönem Attika mezar kabartmalarında kadınların üzüntülü veya düşünceli olma durumunu anlatırken, Hellenistik Dönem heykelinde sepulkral bağlamını yitirerek kentin önde gelen kadın vatandaşlarının tasvirinde, özellikle onurlandırma heykellerinde tercih edilmeye başlanmıştır (Şahin 2000: 59-69). 
yapılmıştır (Res. 4a). Burun ve ağız kısmı tahrip olmuştur. Bayanın saçları alın ortasından ikiye ayrılıp yanlara ve geriye doğru dalgalı olarak işlenmiştir. Olasılıkla saçlar arkada topuz yapılmıştır. Chiton ve himation giyimlidir. Himation başın üzerini de örterek aşağıya iner. Himation kolları da sarmaktadır ve himationun sağ kenarı göğüs hizasından sol omuz üzerine atılmıştır. Sol taraftaki himation kumaşı sol kola dolanarak aşağıya doğru uzanmaktadır. Kadın başı dar alına sahiptir. Sağ kaş tahrip olmuştur. Gözler iri ve badem şeklindedir. Üst göz kapağı kalın ve etli işlenmiştir. Alt göz kapağı ise daha ince yapılmıştır. Yüz, çene yuvarlak ve dolgundur (Res. 4b).

Himationun altında yuvarlak yakalı chiton giyimlidir. Chitonun yakasında boynun her iki tarafından aşağıya doğru inen kumaş kıvrımları "V" şekli oluşturmaktadır. Sağ kol dirsekten kıvrılarak hafifçe yukarıya ve sol göğüs üzerine doğru uzatılmıştır ve sol göğüs üzerine düşen himation kumaşını tutar pozdadır. Sağ el bilek hizasından itibaren himationun dışında gösterilmiştir. Sol kol yan tarafta aşağıya doğru uzanmıştır. Görülebildiği kadarıyla sol elin bilek hizasından itibaren açıkta bırakıldığı anlaşılmaktadır. Büst karın hizasında bitirilmiştir.

Stel üzerinde betimlenen büst pudicitia tipindedir. Pudicitia tipinde yapılmış figürler genellikle mezar stellerinde büst şeklinde olmayıp tüm vücudun betimlendiği örneklerdir. Mysia Bölgesinin mezar stelleri kendi içinde dört gruba ayrılarak incelenmişlerdir. Bu tipler arasında bizim örneğimize en yakın olanı "Pudicitia Saufeia" tipidir. Özellikle himationun örtülmesi ve să̆ kolun himationun sol kenarını tutuşu bu tip ile örtüşmektedir. Pudicitia Saufeia tipi Linfert'e göre, en çok sevilen Pudicitia tiplerindendir. Hellenistik örnekler MÖ 2. yüzyılın ikinci yarısında Rhodos, Kos, Smyrna, Ephesos, Sardes ve Pergamon'da karşımıza çıkmaktadır (Linfert 1976: 148, Taf. 5. Abb. 23).

Stelde betimlenen bu tipe benzer örneklerden biri Selçuk Müzesinde korunan envanter numarası 422 olan mezar stelidir (Pfuhl- Möbius 1979: Taf. 305, Nr. 2125). Boynun altında bulunan yuvarlak yakalı chiton, boynun her iki tarafından aşağıya doğru inen kıvrımların "V" şeklini oluşturması, sağ kolun dirsekten kırılarak çapraz şeklinde yükselerek chiton kıvrımlarını tutması Doğanhisar steliyle benzeyen stilistik özelliklerdir. Bir başka örnek İstanbul Arkeoloji Müzesinde korunan envanter numarası 4496 olan mezar stelidir. (Pfuhl-Möbius 1979: 2128). Boyundan inen chiton kıvrımlarının sağ eli gergin sararak yukarıya çapraz bir şekilde yönelip "V" kıvrımı oluşturması, sağ elin dirsekten kırılarak hafifçe yukarıya doğru uzanıp sol taraftaki chiton yakasını tutması ve yuvarlak dolgun yüz yapısı, güçlü çene yapısı her iki stelde de ortak olan özelliklerdir. Bir diğer örnek Bursa Arkeoloji Müzesinde korunan MS 1. yüzyılın ilk çeyreğine tarihlenen 3136 envanter numaralı mezar stelidir (Şahin 2000: 45, Levha LXXIII, KB, 20). Oldukça etli ve dolgun, yuvarlak bir yüze sahip olan kadın büstünün başı üzerindeki saçın alın ortasından ikiye ayrılarak ince çizgiler şeklinde başını örten himationun altına doğru gitmesi ve gözlerin gölgeli kaşlar altında yüzeysel olarak verilmesi Doğanhisar stelindeki kadın büstüyle karşılaştırılabilir. Büst bu haliyle Julius-Claudiuslar Dönemine tarihlenen Erzurum'dan bir portre baş (İnan-Rosenbaum II, Taf. 190. 1-2) ve MS 1. yüzyılın ilk çeyreğine tarihlenen Aquileia'dan bir mezar stelindeki başla da karşılaştırabilir (Pflug1989:192 vd. Kat. Nr. 91, Taf. 19.3).

Büstün hemen altında ise beş satırdan oluşan Grekçe yazıt yer almaktadır.

$$
\begin{gathered}
\text { MARKEMOC. U } \\
\text { KAINEIKHCUN } \\
\text { EUNOIKONI } \\
\text { DMAOUGOATRI } \\
\text { MNHWHCENQ } \\
\text { KEN }
\end{gathered}
$$


Çevirisi: Yazıt "Marcus Aurelius ve Nike kızlarının hatırası için" şeklinde okunmaktadır6.

"Marcus Aurelius ve Nike, kızlarının hatırası için" şeklinde çevirisi yapılmıştır. Kızın adı okunmadığı için stel sahibinin adını söyleyebilmek mümkün değildir.

Yazıt, stelin tarihlendirilmesinde bize yardımcı olmamaktadır. Bölgenin diğer stellerine göre özenli ve kaliteli bir işçiliğe sahiptir. Bir tapınak cephesinde görebileceğimiz tüm mimari elemanlar detaylı ve eksiksiz olarak işlenmiş̧ir. Buna karşın büstün işlenişi için aynı ifadeyi kullanamıyoruz. Belki de kullanılan malzemenin yerel kireçtaşı olması bu sonucu doğurmuştur. Mysia Bölgesi mezar stelleri arasında yer alan Pudicitia Saufeia tipinin Cumhuriyet Döneminde mezar stellerinde sevilerek kullanıldığını biliyoruz. Ayrıca plasterler üzerinde görülen sarmaşık bezemesinin ranke süslemesini anımsatması ve bu süslemenin Augustus Döneminde sıklıkla kullanılması tarihleme için bize yardımcı olacak bir unsurdur7 7 Tüm bu nedenlerle bu stel için tarih olarak MS 1. yüzyılın ilk çeyreğini önermek istiyoruz.

\section{SONUÇ}

Çalışmamıza konu olan mezar stelinin üzerindeki figürün basit işçiliğine rağmen doğal bir oranlama göstermesi, kendine has duruşunun olması, plastik yapısı, canlı yüz anlatımı, duygunun verilişi ve yumuşak işçilikleriyle büyük olasılıkla çok iyi yerli bir usta tarafından, yerel bir atölyede üretilmiş olduklarını akla getirmektedir. Dolayısıyla stelin biçimsel özellikleri, betimlenen öğeleri, kadın figürünün stilistik özellikleri tümü göz önüne alındığında Konya Arkeoloji Müzesinde korunan stelin genel yapı olarak daha çok Dağlık Phrygia stellerinin etkisinde üretim yapan bir atölyede yapıldığını düşündürmektedir.

Stelin bezeme özellikleri ve betim alanında görülen figürün fizyonomik ve stilistik özellikleri bir arada değerlendirildiğinde Doğanhisar stelini MS 1. yüzyılın ilk çeyreğine tarihlendirmeyi uygun gördük.

\section{SUMMARY}

One of the centers of the geography of Central Anatolia that has witnessed the settlement of several civilizations since the oldest periods of the history is Doğanhisar district which needs to be examined archeologically. This district is located $122 \mathrm{~km}$ west of Konya and established on the northeastward foothills of the Sultan Mountains. But, the localization of the settlement is still contradictive. Doğanhisar is the neighbour of Ilgın in the east, Hüyük in the south, Isparta in the west, Akşehir in the northwest and Ilgın's Argithanı town in the north. A lot of archaeological findings were obtained by the archaeological researches in the center of the district.

In this study, the funerary stele with the inventory number 2006.6.1 in Konya Archeological Museum is evaluated. This stele was found during a sewerage work conducted in front of the Ezze Mosque on the Cumhuriyet Road, in Ezze Street in Doğanhisar. The stele is made of local limestone and was constructed so as to be similar to the frontage of a temple and shaped like a longitudinal rectangle narrowed from bottom to top. A variety of floral decorations are seen such as palmetto, creeper, and ranke (Convoluted bough) on the frontone and bedplate parts of the stele. Pudicitia-type woman eikon and the Greek inscription consisting of five lines (Marcus Aurelius and Nike had the grave stele built in the memory of their daughters) could be seen on the chassis of the stele.

The stele of Doğanhisar reflects the local style of the Phrygia region in terms of the features of workmanship and composition. It is estimated that this funerary stele was constructed in the first quarter of the 1st-century $\mathrm{AD}$ when the stylistic points of the figure described and the decoration elements imaged on the stele were analyzed typologically.

\footnotetext{
${ }^{6} \mathrm{~K} ı \mathrm{z}$ evlat kelimesi tekil. Çoğulluk Türkçeden kaynaklanıyor. Ölen kızın babası Marcus Aurelius, annesi Nike'dir. Kızın ismi okunamıyor. Yazıtın çevirisinde yardımlarını esirgemeyen M. Aydaş'a çok teşekkür ederiz.

7 Ranke bezemelerinden sonra farklı tipte çiçek bezeklerinin kullanılması Ara Pacis kıvrık dal bezemeleri içerisinde de görülmektedir. (Zanker 1988: Fig. 140). Ranke bezemeleri için detaylı bilgi bkz. (Schede 1909: Taf. XXXI.I).
} 


\section{KAYNAKÇA}

CALDER, William Moir (1956). Monuments from Eastern Phrygia. Monumenta Asiae MinorisAntiqua. [MAMA VII]. Manchester: Manchester University Press.

COX, Christopher William Machell-ALAN, Cameron (1937). Monuments from Dorylaeum and Nacolea (MAMA V). Manchester: Manchester Univercity.

EMEKLİ ÖZDEMIR, Miyase (2005). Konya Arkeoloji Müzesindeki Roma Dönemi Mezar stelleri. Yüksek Lisans Tezi. Konya: Selçuk Ü.

IŞIK, Emel (1988). Lydia Mezar Stelleri. Doktora Tezi. Erzurum: Atatürk Ü.

İNAN, Jale-ROSENBAUM, Alföldi Elisabeth (1966). Roman and Early Byzantine Portrait Sculpture in asia Minor. London: Oxford University.

KONYALI, Hakkı İbrahim (1945). Nasrettin Hocanın Şehri Akşehir. İstanbul: Numune Matbaası.

KSENOPHON (1962). Anabasis. çev. Hayrullah Örs. İstanbul: Millî Eğitim Bakanlığı Yayınları. 2. bs.

LINFERT, Andreas (1976). Kunstzentren hellenistis cher Zeit. Studien an weiblichen Gewand figuren. Wiesbaden: Franz Steiner.

MCLEAN, Bradley Hudson (2002). Greekand Latin inscriptions in the Konya Archaeological Museum (Regional epigraphic Catalogues of Asia Minor IV). Ankara: British Institute of Archaeology.

PFLUG, Römische Hermann(1989). Porträtstelen in Oberitalien: Untersuchungen zur Chronologie. Typologieund ikonographie. Germany: Mainz am Rhein : Philippvon Zabern.

PFUHL, Ernst-MÖBİUS, Hans (1979). Die Ostgriechischen Grabreliefs. II. Germany. Mainz: Verlag Philippvon Zabern.

RAMSAY, Wiliam Mitchell (1939) Anadolu'nun Tarihi Coğrafyası. çev. Mihri Pektaş. Ankara: Millî Eğitim Bakanlığı Yay.

RAMSAY, WiliamMitchell (1887) . "The Cities and Bishoprics of Phrygia (Continued)." The Journal of Hellenic Studies (8): 461-519.

SCHEDE, Martin (1909). Antikes Traufleisten Ornament. (Zur Kunstgeschichtedes Auslande). Strassburg: Heitz.

SEVIN, Veli (2001) Anadolu'nun Tarihî Coğrafyası. Ankara: Türk Tarih Kurumu Yay.

ŞAHIN, Mustafa (2000). Miletopolis Kökenli Figürülü Mezar Stelleri ve Adak Levhaları. Ankara: Türk Tarih Kurumu Yay.

TALBERT, Richard John Alexander (2000). Barrington Atlas of the Greek and Roman World: Map ByMap Directory C. I. Princeton: Princeton Univercity.

TIRPAN, Ahmet-SÜTÇÜOĞLU, Okay (2012). "Doğanhisar'ın Tarihi Coğrafyası. Tyraion, Thiymbrion, Hadrianapolis adlarının yanlış lokalizasyonuna dair kanıtlar ve Doğanhisar antik kent dokusunun tanımlanması". I Ulusal Doğanhisar sempozyumu bildiriler kitabı. Konya.

UÇAN, Fevzi (1988). Ünitelerimizde Konya İli. Konya: Olba Kitap Evi. 2. bs.

WAELKENS, Marc (1986). DieKleinasiatischenTürsteine. Typologische und Epigraphische. Untersuchungen der Kleinasiatischen Grabreliefs mit Scheirtü. Mainz: Philippvon Zabern.

YAYLALI, Abdullah (1979). Hellenistik Devir İzmir Kökenli Figürlü Mezar Stelleri. Yayınlanmamış Doçentlik Tezi. Erzurum: Atatürk Ü.

ZANKER, Paul (1988). ThePower of Images in the Age of Augustus. AnnArbor: The University of Michigan Press.

ZANKER, Paul (1994). “The Hellenistic Grave Stelai From Smyrna: Identity and Self-image in the Polis. Image sand Ideologies". Self-Definition in the Hellenistic World. ed. Antony W. BullochErich S. Gruen- A. A. Long- Andrew Steward. University of California Press. 212-230. 
EKLER

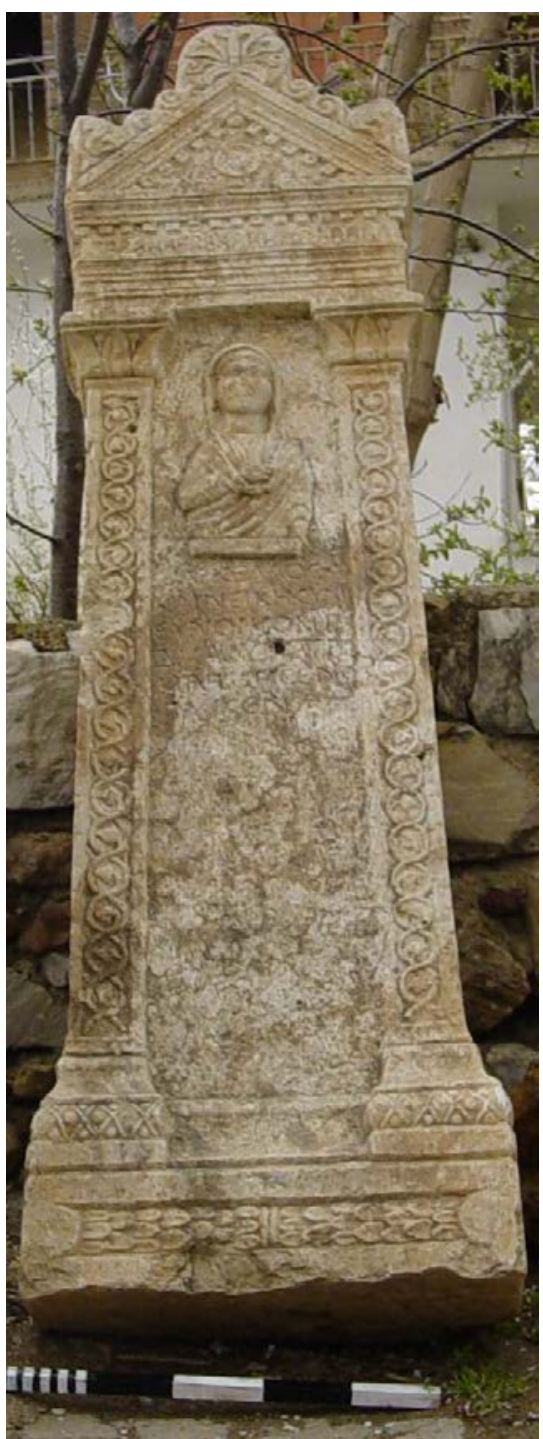

Resim 1a: Doğanhisar mezar steli

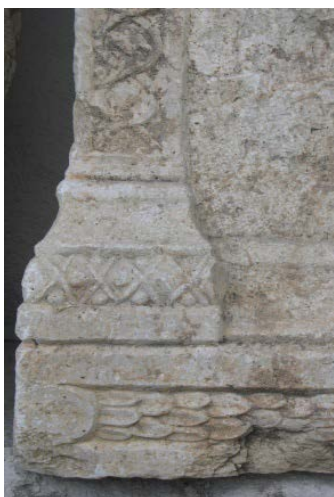

Resim 2a: Plaster kaide detayı

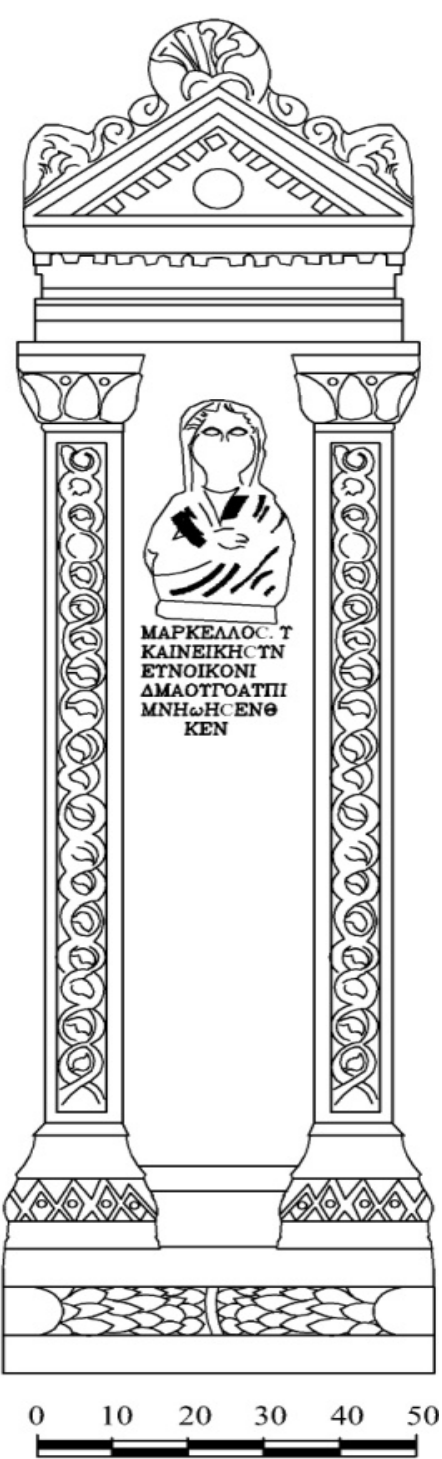

Resim 1b: Doğanhisar mezar stelinin çizimi

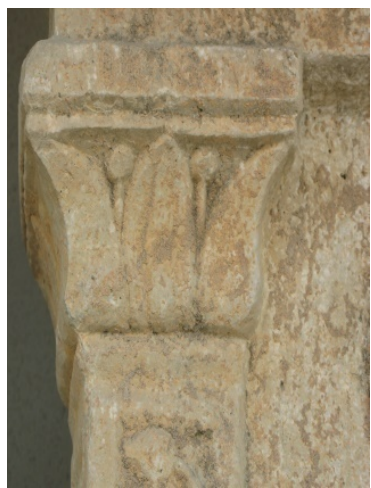

Resim 2b: Plaster başlık detayı 


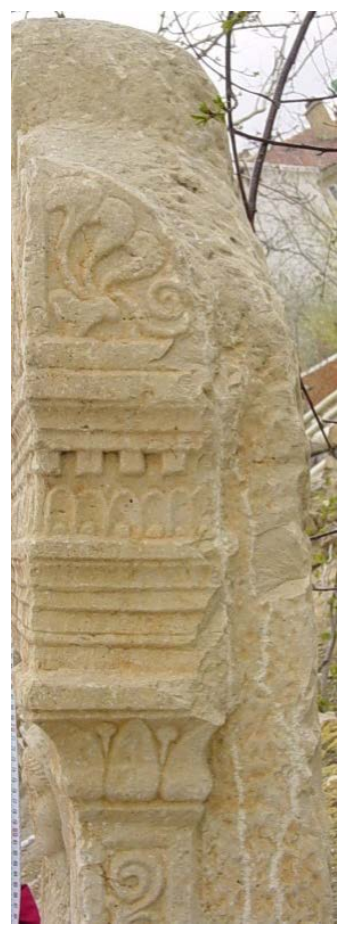

Resim 3: Plasterin yan yüz detayları

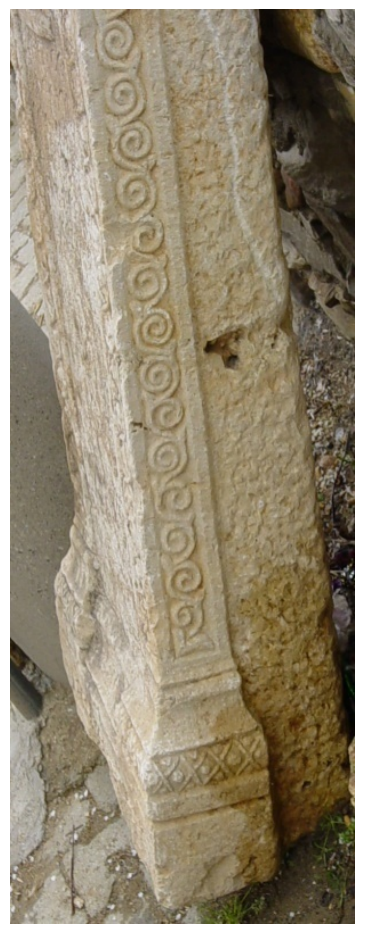

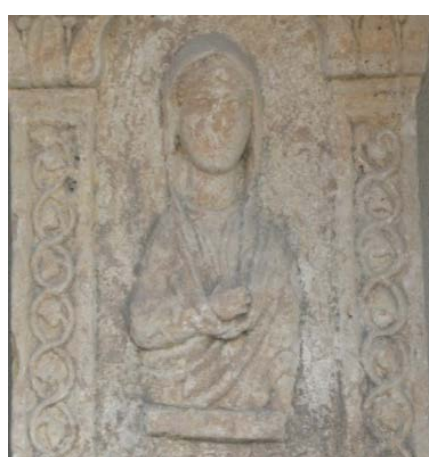

Resim 4a: Figür

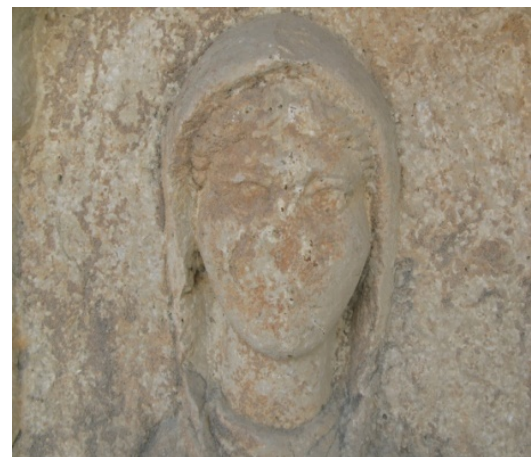

Resim 4b: Figür Detayı 